\title{
The effect of porcine circovirus type 2 (PCV2) vaccination of male piglets on sperm quality at the age of puberty
}

\author{
Theodoros Karapanos ${ }^{1}$, Ioannis Tsakmakidis ${ }^{1}$, Spyridon Kritas ${ }^{2}$, Panagiotis Tassis ${ }^{1}$, \\ Georgios Tsousis ${ }^{1}$, Eleni D. Tzika ${ }^{1}$
}

\begin{abstract}
Aristotle University of Thessaloniki, Faculty of Health Sciences, School of Veterinary Medicine, ${ }^{1}$ Department of Clinics, Clinic of Farm Animals, ${ }^{2}$ Department of Microbiology and Infectious Diseases, Thessaloniki, Greece
\end{abstract}

Received January 29, 2019

Accepted April 23, 2019

\begin{abstract}
The objective of the study was to investigate the effect of porcine circovirus type 2 (PCV2) vaccination in piglets on sperm quality of young boars. A total of 136 sows were divided in four groups of 34 animals each (17 vaccinated with Circovac ${ }^{\circledR}$, Merial and 17 unvaccinated in each group). A total of 1200 piglets were selected, half of which were vaccinated against PCV2 on the $21^{\text {st }}$ day (Porcilis ${ }^{\circledR}$ PCV, MSD) and the other half was left unvaccinated. Four groups of 300 pigs each were formed as follows: PS group (vaccinated sows + piglets), S group (vaccinated sows + unvaccinated piglets), $\mathrm{P}$ group (unvaccinated sows + vaccinated piglets), $\mathrm{C}$ group (unvaccinated sows + piglets). Furthermore, 80 boars (20 piglets per group) were selected and slaughtered at the age of 5.5 months and weight of $95 \pm 5.5 \mathrm{~kg}$ and their epididymal sperm was collected and evaluated for motility and kinetics, concentration and morphology. Additionally, 10 pigs from each group were used for blood sampling and serological testing for PCV2 IgM and IgG antibodies at the age of $21,70,110$ and 150 days. The IgG and IgM patterns suggested that the piglets were coming into contact with PCV2 early in life. The S group demonstrated significantly lower curvilinear velocity (VCL, $\mu \mathrm{m} / \mathrm{s}$ ), amplitude of lateral head displacement (ALH, $\mu \mathrm{m})$ and significantly higher head abnormalities $(\%)$ compared to other groups $(P<0.05)$. In conclusion, vaccinated young boars showed some improved epididymal sperm kinetic indices and head morphology.
\end{abstract}

Boar, epididymal sperm, sperm kinetics, head morphology

Porcine circovirus type 2 (PCV2) was first described in 1997 as the causative agent of the post weaning multisystemic wasting syndrome (Clark 1997). The first reports for late-term abortions, birth of stillborn and mummified piglets due to PCV2 infection go back as far as 1999 (West et al. 1999). The main route of transmission of PCV2 in swine populations is faecal-oral (Segales et al. 2005). Detection of PCV2 DNA has been reported in secretions and excretions including faeces, urine, saliva, ocular fluid, nasal secretions, colostrum, and semen of infected pigs (Shibata et al. 2003). The virus infects the embryo, while the sow can be infected either horizontally or by infected boar semen.

Mature boars infected with PCV2 (naturally or experimentally) are often free of clinical signs but they can shed the virus in semen for a long period (Gerber et al. 2010). The PCV2 viral antigen has been detected in the reproductive organs (testes) and tissues (germinal epithelial cells, epididymis) of naturally and experimentally infected boars. When semen samples of naturally infected boars, between 33.9-149.3 weeks of age were tested, it was more likely semen that had been collected from younger boars to be positive to PCV2 DNA. However, PCV2 DNA in semen does not appear to have detrimental effects on sperm morphology (McIntosh et al. 2006).

Several commercial PCV2 vaccines are currently available for use in piglets or adult animals, considered to be able to reduce the clinical signs of a PCV2 infection at a farm level. It has also been reported that vaccination against PCV2 in experimentally (S eo et al. 
2011) or naturally (Alberti et al. 2011) infected mature boars can decrease the duration of viral shedding in semen. Since a very high percentage of boars become naturally infected by PCV2 later in life, it is of importance to assess whether the vaccination early in the boar's life with a commercial PCV2 vaccine still has a beneficial effect. Therefore, the objective of the present study was to determine the effect of vaccination against PCV2 early in the boar's life with or without the vaccination of their mothers on epididymal semen quality.

\section{Materials and Methods}

The study was approved by the Ethics Committee on Animal Use (approval number: 6365) of the School of Veterinary Medicine, Aristotle University of Thessaloniki, Greece, and all operations were carried out according to the university's guidelines for animal research.

For the needs of the study, the vaccine Porcilis PCV MSD-Intervet (Madison NY, USA) was used which induces immunity against PCV2. It contains PCV2 ORF2 subunit antigen $\left(\geq 4.5 \log _{2}\right.$ ELISA units $\left./ 2 \mathrm{ml}\right)$ expressed on baculovirus. It was administered intramuscularly twice at a dose of $2.0 \mathrm{ml}$. The onset of immunity occurs in 2 weeks, with a duration of 22 weeks (Reg.No.G.3936/Act 36/1947).

A Greek pig farm of 670 sows was selected for the trial. The herd was naturally infected with PCV2 according to routine serological testing performed prior to the beginning of our experiment. A total of 136 sows were divided into four groups of 34 animals each (17 vaccinated and 17 unvaccinated in each group) with an interval of one week between the groups according to the production system of the farm; resulting in 68 vaccinated and 68 unvaccinated sows. The vaccinated sows received double vaccination at 60 and 30 days before farrowing with a commercial vaccine (Circovac ${ }^{\circledR}$, Merial, Lyon, France) while the unvaccinated sows received placebo (Normal Saline) on the same days.

A total of 1200 born piglets were selected (600 piglets from vaccinated and 600 piglets from unvaccinated sows) to assess the efficacy of different vaccination schedules against PCV2 on the piglets' health and performance (under publication). Vaccination and placebo (Diluvac Forte ${ }^{\mathbb{B}}$, Diluent, MSD-Intervet, Madison NY, USA) were administered at 21 days of the piglet's life (according to the manufacturer's instructions) with a commercial PCV2 vaccine (Porcilis ${ }^{\circledR}$ PCV, MSD-Intervet, Madison NY, USA) and in accordance with the welfare rules.

This resulted in 4 groups of piglets divided as follows: a) 300 pigs: vaccinated sows - vaccinated piglets (SP group), b) 300 pigs: vaccinated sows - unvaccinated piglets (S group), c) 300 pigs: unvaccinated sows vaccinated piglets (P group), d) 300 pigs: unvaccinated sows - unvaccinated piglets (C, control group).

Piglets of each group were marked with an ear tag in the left ear in colour according to the experimental group to which it belonged. At the age of 21 days, 20 healthy male piglets from each group (in total 80 ) were selected for serological and semen tests. All selected piglets were healthy at the beginning of the experimental period (no diarrhoea, coughing, or morphological abnormalities), their body weight was over $5 \mathrm{~kg}$ and they came from sows of 4-6 parities. Additionally, ten pigs from each group were selected and marked with red ear tag to be used for blood sampling on days $21,70,110$ and 150 of life to detect the presence of $\operatorname{IgM}$ and $\operatorname{IgG}$ against PCV2.

Epididymal sperm sample collection

All male piglets from each group at the age of 5.5 months and weight of $95 \pm 5.5 \mathrm{~kg}$ were slaughtered and both testes and epididymides contained in scrotal sacs were immediately removed, placed in bags into an isothermal box $\left(4-5^{\circ} \mathrm{C}\right)$ and transferred to the laboratory in less than $2 \mathrm{~h}$. Each epididymal cauda was carefully separated from the testis using a scalpel blade and was placed in a Petri dish containing $5 \mathrm{ml}$ of pre-warmed phosphate buffered saline (PBS) buffer at $37^{\circ} \mathrm{C}$. After that, many sections by the blade were performed in each separated epididymal cauda. Then they were washed by a standard volume of $5 \mathrm{ml}$ of PBS to collect epididymal spermatozoa into the Petri dish. The collected epididymal sperm was washed in PBS by centrifugation $(400 \times g, 10 \mathrm{~min})$, the supernatant was removed, and $1 \mathrm{ml}$ of PBS was added to resuspend the sperm sample for the following analysis process.

Epididymal sperm quality evaluation

Sperm kinetics were evaluated using a computer-assisted semen analysis (CASA-Sperm Class Analyser ${ }^{\circledR}$, Microptic S.L., Automatic Diagnostic Systems, software version SCA $^{\circledR}$ v.5.2.0.0, Spain) and a microscope ( $\times 100$; AXIO Scope A1, Zeiss, Germany) accomplished with a heating stage. Ten $\mu$ l of each semen sample were placed on the preheated Makler chamber (Makler ${ }^{\circledR}$ counting chamber, $10 \mu \mathrm{m}$ deep, Sefi Medical Instruments, Israel) at $37^{\circ} \mathrm{C}$, and triplicates of the assessment were performed. The following CASA motility indicators and kinetics were estimated: total motility (\%), progressive motility (\%), rapid, slow and immotile spermatozoa (\%), VCL-curvilinear velocity $(\mu \mathrm{m} / \mathrm{s})$, VSL-straight line velocity $(\mu \mathrm{m} / \mathrm{s})$, VAP-average path velocity $(\mu \mathrm{m} / \mathrm{s})$, ALHamplitude of lateral head displacement $(\mu \mathrm{m})$, BCF-beat/cross-frequency $(\mathrm{Hz})$, LIN-linearity $(\mathrm{VSL} / \mathrm{VCL} \times 100)$, STR-straightness (VSL/VAP $\times 100)$, and WOB-wobble $(\mathrm{VAP} / \mathrm{VCL} \times 100)$.

The CASA system software was configured as follows: eight fields and $>500$ spermatozoa, 25 frames $/ \mathrm{s}$, region of particle control 10-18 $\mu \mathrm{m}$, progressive movement of $>45 \%$ of indicator STR, circumferential movement $<$ 
$50 \%$ of indicator LIN, field depth of $10 \mu \mathrm{m}$. The objects incorrectly identified as spermatozoa were manually removed from each picture.

Assessment of sperm morphology

Sperm morphology was evaluated by the SpermBlue staining method (SpermBlue ${ }^{\circledR}$ 08029, Microptic S.L., Spain) according to the manufacturer's instructions. Spermatozoa were assessed microscopically $(\times 400)$ and classified as normal or with morphological abnormalities (head, neck, tail). Totally, 200 spermatozoa were scored and the $\%$ ratio per sample was calculated.

Determination of sperm concentration

The concentration of each epididymal sperm sample was determined according to Pruneda et al. (2005) with some modifications. Briefly, after the transfer of the epididymites in the lab and before any other process, a small piece of $30 \mathrm{mg}$ of tissue was gently cut from each epididymis region to be used for the determination of sperm concentration. Those tissues were bisected further into a Petri dish with PBS. Then a standard volume of $2 \mathrm{ml}$ of PBS was added and the solution was collected and centrifuged at $400 \times \mathrm{g}$ for $10 \mathrm{~min}$. After centrifugation, the supernatant was discarded, the sperm pellet was resuspended in $2 \mathrm{ml} \mathrm{PBS}$, and the sperm concentration was determined by an improved Neubauer haemocytometer (Neubauer Improved Counting Chamber, Paul Marienfeld Gmbh \& Co. KG, Germany).

\section{Serology}

The presence of IgM and IgG against PCV2 was detected at Dierengezondeheidszorg Vlaanderen vzw, Torhout, Belgium using a commercially available ELISA kit (Ingezim Circovirus IgG/IgM ELISA, Ingenasa, Madrid, Spain) based on the use of 3 monoclonal antibodies (MAb) specific for porcine circovirus, porcine IgM specific $\mathrm{mAb}$, porcine IgG specific $\mathrm{mAb}$ and a recombinant antigen. With this assay it is possible to differentially detect IgM and IgG antibodies specific to circovirus type 2 in porcine serum samples. The ELISA tests were performed according to the manufacturer's instructions.

The statistical analysis performed using the Statistical Analysis Systems version 9.3 (SAS Institute Inc., Cary, N.C., USA). Normality of the data was tested using Shapiro-Wilk test (PROC UNIVARIATE). Indicators that did not follow normal distribution were normalized by square root transformation. For reasons of clarity, the means and SEM of the data were presented. Statistical analysis was conducted with type III Anova Model of General Linear Models. Pairwise comparisons were performed with Tukey's Studentized Range (HSD) test. Significant difference was defined as $P<0.05$.

\section{Results}

The number of samples positive for IgG antibodies was high in groups $\mathrm{P}$ and SP four weeks after vaccination until the start of the finishing period, whereas the samples positive for IgM antibodies were high between 7 and 10 weeks of age. The number of samples positive for IgG antibodies was high in groups $\mathrm{S}$ and $\mathrm{C}$ during the finishing period, whereas the samples positive for IgM antibodies were high at 7 weeks of age and at the beginning of the finishing period. The relative results are summarized in Figs 1, 2.

The results of epididymal sperm motility are presented in Table 1. Even though the values found in vaccinated groups of piglets were higher, no significant differences were observed between the 4 treatment groups. The results for epididymal sperm kinetics are presented in Table 2. Significantly lower values of ALH were noticed in group S compared to groups

Table 1. Assessment of sperm motility by the computer assisted semen analysis system (CASA) (mean \pm SEM).

\begin{tabular}{lccccc}
\hline & \multicolumn{5}{c}{ Groups } \\
\cline { 2 - 6 } Indicator & $\mathrm{C}$ & $\mathrm{P}$ & $\mathrm{SP}$ & $\mathrm{S}$ & $P$-value \\
& $\mathrm{n}=19$ & $\mathrm{n}=20$ & $\mathrm{n}=20$ & $\mathrm{n}=19$ & \\
\hline Progressive & $25.09 \pm 5.16$ & $36.49 \pm 5.69$ & $32.97 \pm 5.75$ & $23.30 \pm 5.74$ & 0.294 \\
motility (\%) & $43.41 \pm 7.29$ & $62.05 \pm 6.87$ & $55.77 \pm 7.06$ & $39.23 \pm 7.33$ & 0.093 \\
Total motility (\%) & & & & & \\
\hline
\end{tabular}

$\mathrm{SP}=$ vaccinated sows - vaccinated piglets group; $\mathrm{S}=$ vaccinated sows - unvaccinated piglets group; $\mathrm{P}=$ unvaccinated sows - vaccinated piglets group; $\mathrm{C}=$ unvaccinated sows - unvaccinated piglets group; SEM - standard error of the mean 
$\mathrm{P}$ and SP $(P=0.002)$. Similarly, VCL values were lower for group $\mathrm{S}$ compared to groups $P$ and SP $(P=0.045)$. No significant differences were found for the remaining indicators between groups. The results for epididymal sperm concentration and morphology are presented in Table 3. Head abnormalities (\%) were significantly higher in group S compared to group $\mathrm{P}(P=0.033)$. No significant differences were noticed for the remaining tested indicators between groups.

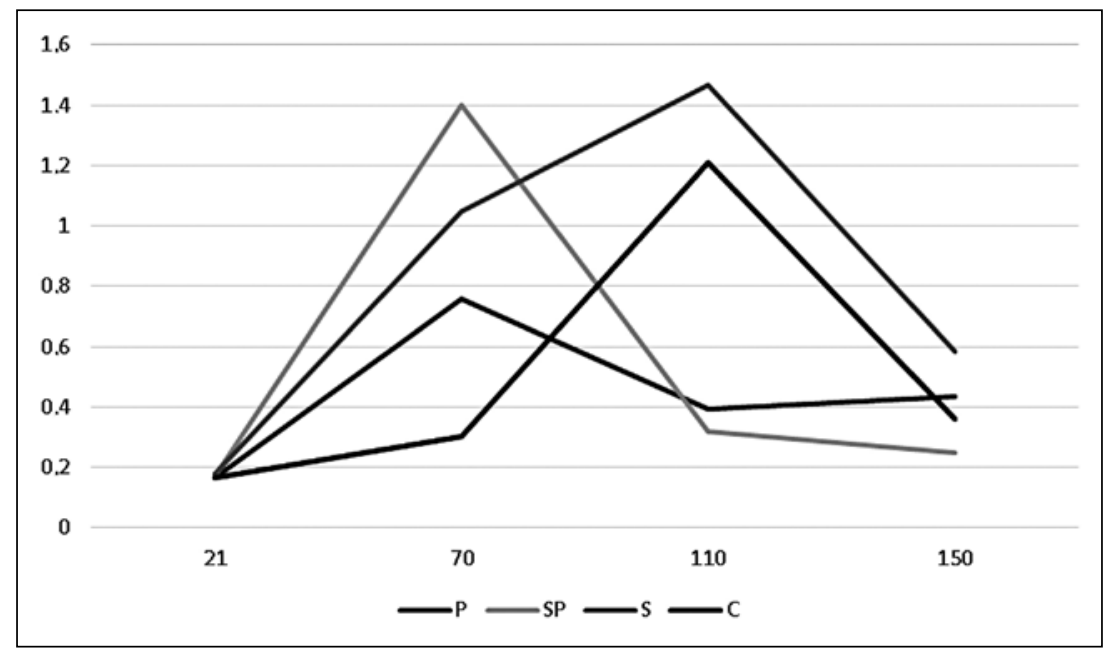

Fig. 1. Mean optical density (OD) values for IgM antibodies by vaccination group and sampling day. $\mathrm{SP}=$ vaccinated sows - vaccinated piglets group; $\mathrm{S}=$ vaccinated sows - unvaccinated piglets group; $\mathrm{P}=$ unvaccinated sows - vaccinated piglets group; $\mathrm{C}=$ unvaccinated sows - unvaccinated piglets group

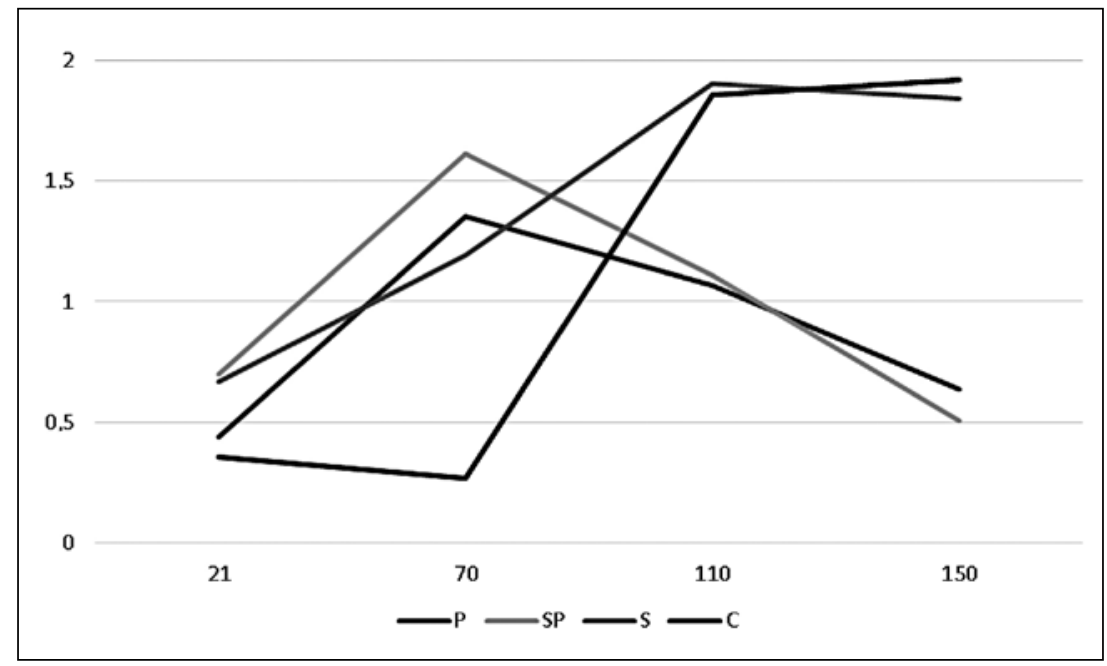

Fig. 2. Mean optical density (OD) values for IgG antibodies by vaccination group and sampling day. $\mathrm{SP}=$ vaccinated sows - vaccinated piglets group; $\mathrm{S}=$ vaccinated sows - unvaccinated piglets group; $\mathrm{P}=$ unvaccinated sows - vaccinated piglets group; $\mathrm{C}=$ unvaccinated sows - unvaccinated piglets group 
Table 2. Assessment of sperm kinetics by computer assisted semen analysis system (CASA) (mean \pm SEM).

\begin{tabular}{|c|c|c|c|c|c|}
\hline \multirow[b]{2}{*}{ Indicator } & \multicolumn{4}{|c|}{ Groups } & \multirow[b]{2}{*}{$P$-value } \\
\hline & $\begin{array}{c}\mathrm{C} \\
\mathrm{n}=19\end{array}$ & $\begin{array}{c}\mathrm{P} \\
\mathrm{n}=20\end{array}$ & $\begin{array}{c}\mathrm{SP} \\
\mathrm{n}=20\end{array}$ & $\begin{array}{c}\mathrm{S} \\
\mathrm{n}=19\end{array}$ & \\
\hline Immotile spermatozoa $(\%)$ & $56.59 \pm 7.29$ & $37.95 \pm 6.87$ & $44.24 \pm 7.06$ & $60.77 \pm 7.33$ & 0.093 \\
\hline $\begin{array}{l}\text { Spermatozoa with } \\
\text { rapid movement (\%) }\end{array}$ & $23.88 \pm 5.35$ & $39.34 \pm 7.22$ & $35.92 \pm 6.51$ & $21.90 \pm 6.27$ & 0.149 \\
\hline $\begin{array}{l}\text { Spermatozoa with } \\
\text { medium movement (\%) }\end{array}$ & $9.50 \pm 1.53$ & $10.79 \pm 1.01$ & $9.17 \pm 1.10$ & $8.08 \pm 1.42$ & 0.512 \\
\hline $\begin{array}{l}\text { Spermatozoa with } \\
\text { slow movement (\%) }\end{array}$ & $10.02 \pm 1.36$ & $11.91 \pm 1.23$ & $10.70 \pm 1.04$ & $9.25 \pm 1.35$ & 0.487 \\
\hline VCL & $47.58 \pm 3.51^{\mathrm{ab}}$ & $56.30 \pm 4.82^{\mathrm{a}}$ & $58.01 \pm 4.81^{\mathrm{a}}$ & $41.94 \pm 4.59^{b}$ & 0.045 \\
\hline VSL & $16.64 \pm 1.87$ & $22.35 \pm 2.54$ & $20.21 \pm 2.70$ & $17.43 \pm 2.67$ & 0.345 \\
\hline VAP & $25.52 \pm 2.48$ & $34.12 \pm 3.77$ & $31.53 \pm 3.65$ & $24.95 \pm 3.68$ & 0.172 \\
\hline LIN & $35.10 \pm 2.80$ & $38.23 \pm 2.22$ & $32.79 \pm 2.44$ & $38.33 \pm 3.12$ & 0.384 \\
\hline STR & $64.33 \pm 2.18$ & $64.77 \pm 1.61$ & $61.89 \pm 1.68$ & $66.43 \pm 1.71$ & 0.359 \\
\hline WOB & $53.33 \pm 2.69$ & $58.34 \pm 2.49$ & $51.94 \pm 2.60$ & $55.15 \pm 3.06$ & 0.371 \\
\hline ALH & $2.57 \pm 0.14^{\mathrm{ab}}$ & $2.82 \pm 0.15^{\mathrm{a}}$ & $3.00 \pm 0.18^{a}$ & $2.11 \pm 0.19^{\mathrm{b}}$ & 0.002 \\
\hline $\mathrm{BCF}$ & $7.30 \pm 0.20$ & $7.38 \pm 0.18$ & $7.23 \pm 0.35$ & $6.60 \pm 0.40$ & 0.238 \\
\hline
\end{tabular}

Different superscripts $(\mathrm{a}, \mathrm{b})$ denote significant differences between groups $(P \leq 0.05)$

$\mathrm{SP}=$ vaccinated sows - vaccinated piglets group; $\mathrm{S}=$ vaccinated sows - unvaccinated piglets group; $\mathrm{P}=$ unvaccinated sows - vaccinated piglets group; $\mathrm{C}=$ unvaccinated sows - unvaccinated piglets group; SEM - Standard Error of the Mean; VCL - curvilinear velocity $(\mu \mathrm{m} / \mathrm{s})$; VSL-straight line velocity $(\mu \mathrm{m} / \mathrm{s})$; VAP - average path velocity $(\mu \mathrm{m} / \mathrm{s}) ; \mathrm{LIN}$ - linearity (VSL/VCL $\times 100) ; \mathrm{STR}$ - straightness $(\mathrm{VSL} / \mathrm{VAP} \times 100)$; WOB - wobble (VAP/VCL $\times 100) ;$ ALH - amplitude of lateral head displacement $(\mu \mathrm{m})$; BCF - beat/cross-frequency $(\mathrm{Hz})$.

Table 3. Assessment of sperm concentration and morphology (mean \pm SEM).

\begin{tabular}{lccccc}
\hline & \multicolumn{5}{c}{ Groups } \\
\cline { 2 - 5 } Indicator & $\mathrm{C}$ & $\mathrm{P}$ & $\mathrm{SP}$ & $\mathrm{S}$ & $P$-value \\
& $\mathrm{n}=19$ & $\mathrm{n}=20$ & $\mathrm{n}=20$ & $\mathrm{n}=19$ & 0.033 \\
\hline Head abnormalities (\%) & $13.36 \pm 7.72^{\mathrm{ab}}$ & $8.00 \pm 1.43^{\mathrm{a}}$ & $12.29 \pm 2.22^{\mathrm{ab}}$ & $16.76 \pm 2.84^{\mathrm{b}}$ & 0.948 \\
Neck abnormalities (\%) & $10.40 \pm 2.69$ & $10.40 \pm 3.64$ & $9.11 \pm 2.97$ & $8.37 \pm 1.93$ & 0.750 \\
Tail abnormalities (\%) & $16.74 \pm 2.14$ & $28.63 \pm 5.77$ & $23.74 \pm 4.15$ & $18.68 \pm 3.72$ & 0.829 \\
Total abnormalities (\%) & $41.55 \pm 3.31$ & $47.23 \pm 5.27$ & $44.66 \pm 3.84$ & $43.82 \pm 4.57$ & 0.122 \\
Concentration & $44.92 \pm 7.79$ & $72.51 \pm 8.95$ & $59.35 \pm 8.73$ & $47.06 \pm 7.53$ & \\
(millions/ml) & & & & & \\
\hline
\end{tabular}

Different superscripts $(\mathrm{a}, \mathrm{b})$ denote significant differences between groups $(P \leq 0.05)$

$\mathrm{SP}=$ vaccinated sows - vaccinated piglets group; $\mathrm{S}=$ vaccinated sows - unvaccinated piglets group; $\mathrm{P}=$ unvaccinated sows - vaccinated piglets group; $\mathrm{C}=$ unvaccinated sows - unvaccinated piglets group; SEM - Standard Error of the Mean

\section{Discussion}

Previous studies reported that vaccination of mature boars can reduce the virus load and duration of shedding in semen without any major impact on the sperm quality or quantity (Caspari et al. 2011). The importance of the presence of PCV2 in semen of premature boars in relation with its quality after puberty is currently unknown and the purpose of this 
study was to expand the knowledge on this topic. Our study suggested that an improvement of some semen characteristics occurs in the sperm of vaccinated piglets, indicating that early vaccination against PCV2 could alter the sperm quality. Groups P and PS tended to differ non-significantly $(P=0.093)$ suggesting that vaccination against PCV2 early in life could have a beneficial effect on the sperm quality of young boars. Other authors did not find a positive relation between boar vaccination against PCV2 and sperm quality (Gava et al. 2008; Madson et al. 2009).

This difference in young compared to mature boars is probably due to the time of vaccination and the age of the boars. Vaccination early in life protects effectively against the systemic disease caused by PCV2 (SD-PCV2) (Fraile et al. 2012; Martelli et al. 2013) and decreases the virus load in the testes and sexual glands (S eo et al. 2013). Frequently in the field, piglets are exposed to PCV2 after the $42^{\text {nd }}$ day of life (Larochelle et al. 2003). This means that when vaccination is administered on the $21^{\text {st }}$ day of life, there is enough time for the vaccine to induce a strong immune response till the time of exposure. PCV2 vaccines provoke a strong humoral and cellular immune reaction. Neutralizing and total antibodies reach maximum titres approximately 14 to 21 days post vaccination. Neutralizing antibodies are responsible for the protection against SD-PCV2 and the subclinical form and reduction of the virus load to target organs and tissues.

Especially in epididymis, PCV2 is identified at a higher frequency than in other accessory glands of naturally infected boars (Ciacci-Zanella et al. 2008). Epididymis dysfunction seems to lead to a high incidence of sperm with single bent tails and low motility (Kunavongkrit et al. 1988).

Serology indicates an early infection of piglets with PCV2 though an early vaccination increases the IgG level. The IgG level rose in the vaccinated group indicating that the increase was due to the vaccine and not due to the infection with the PCV2 field virus. Vaccinated piglets are protected against the clinical manifestation of the SD-PCV2 and the load of PCV2 -DNA in organs and tissues including the testes, epididymis and semen is lower than in the unvaccinated groups (S eo et al. 2011).

It is important to note that good sperm kinetics positively affect fertility. Kinetic indicators are major predictors of the litter size; VCL has a major effect on the farrowing rate and ALH on the litter size (Juonala et al. 1998; Broekhuijse et al. 2012). Some researchers showed that PCV2 infections of sows lead to a smaller litter size (O'Connor et al. 2001; Ladekjaer-Mikkelsen et al. 2001). We probably also need to consider the sperm quality of boars that were infected with PCV2 some time in their lives, as an indicator that could lead to a smaller litter size on farms with a history of PCV2 infection.

Sperm head abnormalities are classified as important morphological defects which affect fertility (Tsakmakidis et al. 2010), sperm motility, and litter size (Gil et al. 2009; McPherson et al. 2014). The lower the percentage of this indicator the better the sperm quality. In our study, a significant difference was found between the groups, and group $\mathrm{P}$ revealed a significantly lower percentage compared to group $\mathrm{S}$. This difference could be due to higher levels of IgG antibodies in group P compared to other groups and thus better protection against SD-PCV2. Another probable reason for the difference in the quality of semen between vaccinated and unvaccinated animals is that some of the unvaccinated piglets suffered from a subclinical form of the disease (Kumman et al. 2011; Oliver-Ferrando et al. 2016) which increases susceptibility to other infections (Opriessnig and Halbur 2012; Park et al. 2014). Potential infection of the unvaccinated groups from another pathogen [e.g. porcine reproductive and respiratory syndrome virus (PRRSv), porcine parvovirus (PPV), Chlamydia sp., Brucella suis, leptospires] during experimentation resulted in alterations in the quality 
of semen (Teankum et al. 2006; Althouse et al. 2007). Especially PRRSv which appears more often than any other virus in coinfections with PCV2 (Pallarés et al. 2002) does not cause specific lesions in testes and epididymides but alters the sperm quality causing sperm abnormalities, reduced motility, increased ALH and reduced linearity (Sur et al.1997; Schulze et al. 2013).

During experimentation, all the male piglets were kept under the same environmental (ventilation and temperature) and nutritional conditions (no feed restriction, no protein restriction, same feed ratio and nutritional value) that could influence the boar semen quality (Wettemann et al. 1976). The only difference between the groups was vaccination against PCV2. We can conclude that the PCV2 vaccination can have a positive effect on boar semen quality.

In our observations, alterations in epididymal sperm kinetic properties and morphology after vaccination against PCV2 in young boars are noticeable, an improvement occurs which is, however, non-specific in order to consider the PCV2 vaccination as a tool to improve the sperm quality in mature boars at a field level. In conclusion, vaccination against PCV2 at 21 days of life positively affects the young boar's epididymal sperm quality. Further research is needed to confirm and support the results of the present study on a field fertility level.

\section{Acknowledgements}

We would like to thank the owner of the pig farm for the help that he provided during the experimental period and MSD Hellas for financial assistance for the purchase of the vaccination products and for conducting the necessary laboratory examinations (AUTH Research Committee grand number 88384).

\section{References}

Alberti K, Estienne M, Meng X 2011: Effect of vaccination of boar against porcine circovirus type 2 on ejaculate characteristics, serum antibody titers, viremia, and semen virus shedding. J Anim Sci 89: 1581-1587

Althouse GC, Youngquist RS, Threlfall WR 2007: Infectious and noninfectious causes of infertility in boars. In: Youngquist ES, Threlfall WR (Eds): Large Animal Theriogenology. Saunders, St Louis, pp. 722-725

Broekhuijse MLWJ, Sostaric E, Feitsma H, Gadella BM 2012: Application of computer assisted semen analysis to explain variations in pig fertility. J Anim Sci 90: 779-789

Caspari K, Henning H, Schreiber F, Maass P, Gössl R, Schaller C, Waberski D 2011: Impact of porcine circovirus type 2 (PCV2) vaccination on boar semen quality and quantity using two different vaccines. Theriogenology 76: $351-360$

Ciacci-Zanella J, Zanella E, Mores N, Neide M, Kelen A, Giseli R, Almiro D, Gava D 2008: Absence of apoptosis and cellular changes in the reproductive system of boars naturally infected with the porcine circovirus 2 (PCV2). Proc IPVS Congress pp 20-23

Clark EG 1997: Post-weaning multisystemic wasting syndrome. In: Proc Ann Meet Am Assoc Swine Pract 28: 3

Fraile L, Sibila M, Nofrarias M, Lopez-Jimenez R, Huerta E, Lopez-Soria S, Perez D, Segales J 2012: Effect of sow and piglet porcine circovirus type 2 (PCV2) vaccination on piglet mortality, viremia, antibody titre and production parameters. Vet Microbiol 161: 229-234

Gava D, Zanella E, Mores N, Ciacci-Zanella J 2008: Transmission of porcine circovirus 2 (PCV2) by semen and viral distribution in different piglet tissues. Pesq Vet Bras 28: 70-76

Gerber P, Pinto F, Heinamann M, Lobato Z 2010: Detection and dynamics of porcine circovirus 2 shedding in semen using conventional and real-time PCR. Pesq Vet Bras 30: 918-920

Gil MC, Garcia-Herreros M, Baron FJ, Aparicio IM, Santos AJ, Garcia_Marin LJ 2009: Morphometry of porcine spermatozoa and its functional significance in relation with the motility parameters in fresh semen. Theriogenology 71: 254-263

Juonala T, Lintukangas S, Nurttila T, Andersson M 1998: Relationship between semen quality and fertility in 106 AI-boars. Reprod Domest Anim 33: 155-158

Kumman J, Sydler T, Brugnera E, Buergi E, Haessig M, Suter M, Sidler X 2011: Vaccinations of dams increases antibody titer and improves growth parameters in finisher pigs subclinically infected with porcine circovirus type 2. Clin Vaccine Immunol 18: 1644-1649

Kunavongkrit A, Chantaraprateep P, Prateep P 1988: Study on boar infertilities: epididymal dysfunction. Acta Vet Scand Suppl 83: 128-132

Ladekjaer-Mikkelsen AS, Nielsen J, Storgaard T, Botner A, Allan G, McNeilly F 2001: Transplacental infection with PCV-2 associated with reproductive failure in a gilt. Vet Rec 148: 759-760

Larochelle R, Magar R, D'Allaire S 2003: Comparative serologic and virologic study of commercial swine herds with and without postweaning multisystemic syndrome. Can J Vet Res 67: 114-120 
Madson D, Ramamoorthy S, Kuster C, Pall N, Meng X, Halbur P, Opriessnig T 2009: Infectivity of porcine circovirus type 2 DNA in semen from experimentally-infected boars. Vet Res 40: 10

Martelli P, Ardigo P, Ferrari L, Morganti M, De Angelis E, Bonilauri P, Luppi A, Guazzeti S, Caleffi A, Borghetti P 2013: Concurrent vaccination against PCV2 and PRRSV: Study on the specific immunity and clinical protection in naturally infected pigs. Vet Microbiol 162: 558-571

McIntosh KA, Harding JC, Parker S, Ellis JA, Appleyard GD 2006: Nested polymerase chain reaction detection and duration of porcine circovirus type 2 in semen with sperm morphological analysis from naturally infected boars. J Vet Diagn Invest 18: 380-384

McPherson FJ, Nielsen SG, Chenoweth PJ 2014: Semen effects on insemination outcomes in sows. Anim Reprod Sci 151: 28-33

O’Connor B, Gauvreau H, West K, Bogdan J, Ayroud M, Clark EG, Konoby C, Allan G, Ellis JA 2001: Multiple porcine circovirus 2-associated abortions and reproductive failure in a multisite swine production unit. Can Vet J 42: 551-553

Oliver-Ferrando S, Segales J, Lopez-Soria S, Callen A, Merdy O, Joisel F, Sibila M 2016: Evaluation of natural porcine circovirus type 2 (PCV2) subclinical infection and seroconversion dynamics in piglets vaccinated at different ages. Vet Res 47: 121

Opriessnig T, Halbur P 2012: Concurrent infections are important for expression of porcine circovirus associated diseases. Virus Res 164: 20-32

Pallarés FJ, Halbur PG, Opriessnig T, Sorden SD, Villar D, Janke BH, Yaeger MJ, Larson DJ, Schwartz KJ, Yoon KJ, Hoffman LJ 2002: Porcine circovirus type 2 (PCV-2) coinfections in US field cases of postweaning multisystemic wasting syndrome (PMWS). J Vet Diagn Invest 14: 515-519

Park C, Seo H, Park S, Han K, Chae C 2014: Comparison of porcine circovirus type 2 (PCV2)-associated lesions produced by co-infection between two genotypes of PCV2 and two genotypes of porcine reproductive and respiratory syndrome virus. J Gen Virol 95: 2486-2494

Pruneda A, Pinart E, Briz MD, Sancho S, Garcia-Gill N, Badia E, Kadar E, Bassols J, Bussalleu E, Yeste M, Bonet S 2005: Effect of a high semen-collection frequency on the quality of sperm from ejaculates and from six epididymal regions in boars. Theriogenology 63: 2219-2232

Schulze M, Revilla-Fernandez S, Schmoll F, Grossfeld R, Griessler A 2013: Effects on boar semen quality after infection with porcine reproductive and respiratory syndrome virus: a case report. Acta Vet Scand 55: 16

Segales J, Allan GM, Domingo M 2005: Porcine circovirus diseases. Anim Health Res J 6: 119-142

Seo H, Kim D, Oh Y, Kang I, Park C, Jang H, Chae C 2011: Effects of an inactivated Porcine Circovirus Type 2 vaccine on PCV2 virus shedding in semen from experimentally infected boars. Clin Vaccine Immunol 18: 1091-1096

Seo HW, Han K, Oh Y, Kang I, Park C, Chae C 2013: Comparison of three commercial one-dose porcine circovirus type 2 (PCV2) vaccines on PCV2 shedding in semen from experimentally infected boars. Vet Microbiol 164: 145-149

Shibata I, Okuda Y, Yazawa S, Ono M, Sasaki T, Itagaki M, Nakajima N, Okabe Y, Hidejima I 2003: PCR detection of porcine circovirus type 2 DNA in whole blood, serum, oropharyngeal swab, nasal swab, and feces from experimentally infected pigs and field cases. J Vet Med Sci 65: 405-408

Sur JH, Doster AR, Christian JS, Galeota JA, Wills RW, Zimmerman JJ, Osorio FA 1997: Porcine reproductive and respiratory syndrome virus replicates in testicular germ cells, alters spermatogenesis, and induces germ cell death by apoptosis. J Virol 71: 9170-9179

Teankum K, Pospischil A, Janett F, Bürgi E, Brugnera E, Hoelzle K, Polkinghorne A, Weilenmann R, Zimmermann DR, Borel N 2006: Detection of chlamydiae in boar semen and genital tracts. Vet Microbiol 116: 149-157

Tsakmakidis IA, Lymperopoulos AG, Khalifa TAA 2010: Relationship between sperm quality traits and fieldfertility of porcine semen. J Vet Sci 11: 151-154

West K, Bystrom J, Wojnarowicz C, Shantz N, Jacobson M, Allan G, Haines D, Clark E, Krakowka S, McNeilly F, Konoby C, Martin K, Ellis J 1999: Myocarditis and abortion associated with intrauterine infection of sows with porcine circovirus 2. J Vet Invest 11: 530-532

Wettemann RP, Wells ME, Omtvedt IT, Pope CE, Turman EJ 1976: Influence of elevated ambient temperature on reproductive performance of boars. J Anim Sci 42: 664-669 